\title{
Perbandingan Performans Reproduksi Kuda Lokal dan Turunan Thoroughbred di Kota Payakumbuh
}

\section{Reproduction Performance between Local Horse and Descendant of Thoroughbred in Payakumbuh}

\author{
Hendri, Suardi, dan A. Mikail \\ Fakultas Peternakan Universitas Andalas \\ Kampus Unand Limau Manis Padang, 25163 \\ e-mail: hendri_ma@yahoo.co.id
}

(Diterima: 23 Mei 2012; Disetujui: 29 September 2012)

\begin{abstract}
This study aimed to compare the performance of reproduction between local horses and descendant of Thoroughbred in Payakumbuh. In this study used a sample of 60 mares productive which have a complete recording. This research was a field research with survey method. Samples were taken by purposive sampling technique. The parameters were observed in between the age of first marriage, old pregnant, and lust after lambing. The results showed that the average age of first marriage in the Local horse was $26.2 \pm 8.53$ months while on horseback Throughbred derivative obtained at $51.8 \pm 14.5$ months, the average of pregnant time of Local horse was $323.17 \pm 8.55$ days while on horseback derivative Throughbred amounted to $324.37 \pm 14185$ days and the median lust after lambing on Local horse was at $16.37 \pm 9.37$ days while on horseback Throughbred derivative obtained at $10.9 \pm 6.64$ days.
\end{abstract}

Keywords: local horse, Thoroughbred, reproduction performance

\section{PENDAHULUAN}

Sudah sejak lama ternak kuda menempati posisi yang cukup menarik dalam masyarakat, ada yang mengisi peran sebagai kuda pacuan dan ada juga yang memang untuk kehidupan sebagai kuda bendi. Olahraga berkuda mendorong adanya usaha memperbaiki mutu ternak kuda melalui Grading-up kuda lokal dengan kuda Thoroughbred, dan memelihara kuda yang lebih baik. Tujuan utama pengembangbiakan kuda hasil cross breeding ini adalah untuk meningkatkan mutu genetik kuda-kuda lokal yang ada di Sumatera Barat. Pada zaman Kemerdekaan beberapa kali propinsi Sumatera Barat memperoleh ternak bantuan Presiden (Banpres) seperti: tahun 1968, 1974, 1976, 1977, 1979, 1981, dan 1983. Pada waktu itu ternak bantuan yang diterima adalah kuda, sapi, kambing, dan kerbau (Dinas Peternakan Propinsi Sumbar, 1989). Terakhir pada tahun 1989 diterima ternak kuda Banpres sebanyak 6 Ekor pejantan Thoroughbred yang disebar pada berbagai daerah tingkat II di
Sumbar. Dengan adanya bantuan-bantuan tersebut maka sampai sekarang telah terdapat turunan kuda Thoroughbred yang cukup banyak, yang tersebar pada berbagai daerah Kabupaten / Kota di Sumatera Barat.

Jacoeb (1994) menyatakan di Sumatera Barat dilakukan persilangan antara kuda setempat dan kuda Arab. Persilangan ini menghasilkan kuda baru yang disebut kuda Sandel Arab. Silver (1976) menyatakan bahwa kuda keturunan ras Arab dengan Sandel mempunyai tinggi berkisaran 130-140 cm dengan rata-rata $136 \mathrm{~cm}$. Ditambahkan oleh Pordasi (1990), bahwa kuda Sandel Arab yang ada di Sumatera Barat mempunyai proporsi darah Arab sekitar 50 - 75\% dan darah Sandel $25-50 \%$.

Ternak kuda mempunyai panjang badan uterus (corpus uteri) $25 \mathrm{~cm}$, tanduk $8-10 \mathrm{~cm}$ dan servik kuda secara relatif halus tetapi menjulur cukup jauh arah kaudal menuju vagina (Manan, 2002). Pada ternak kuda vagina berukuran panjang $20-30 \mathrm{~cm}$ dan diameter $10-$ $13 \mathrm{~cm}$ (Toelihere, 1985). Ovarium kuda betina 
seperti halnya testes pada kuda jantan merupakan organ berpasangan yang memiliki dua fungsi yaitu, fungsi gametogenik sebagai penghasil sel telur dan fungsi endokrin sebagai penghasil hormon reproduksi. Menurut McDonald dan Pineda 1989 dalam Jamalia, 2006), kedua fungsi saling melengkapi, interdependen dan sama-sama penting dalam keberhasilan proses reproduksi.

Tuba Fallopii pada kuda terdapat sepasang dengan panjang $25-30 \mathrm{~cm}$, berhubungan langsung dengan cornua uteri (Morel, 2002 dalam Jamalia, 2006). Tuba Fallopii dapat dibedakan menjadi tiga bagian, yaitu isthmus yang paling dekat dengan cornua uteri berdiameter $2-5 \mathrm{~mm}$, ampula yang berdekatan dengan ovarium berdiameter $5-10 \mathrm{~mm}$ dan infundibulum yang berhubungan langsung dengan ovarium. Fertilisasi terjadi di ampula, yang memiliki daerah mukosa dengan permukaan bersruktur seperti rambut untuk mentransportasikan telur yang telah dibuahi menuju utero tuba junction (Morel, 2002 dalam Jamalia, 2006).

Uterus kuda merupakan sruktur memanjang yang menghubungkan cervix dengan tuba Fallopii. Uterus dibagi menjadi dua bagian yaitu bagian badan atau corpus dan tanduk atau cornua. Corpus uteri pada kuda normal panjangnya $18-20 \mathrm{~cm}$ dan diameter $8-12 \mathrm{~cm}$. Bagian cornua panjangnya $25 \mathrm{~cm}$ dengan diameter $4-6 \mathrm{~cm}$ pada pangkal cornua $1-2 \mathrm{~cm}$ pada saat mendekati tuba Fallopii. Ukuran uterus dipengaruhi oleh usia dan seringnya partus. Tipe uterus kuda disebut uterus simpleks bipartitus karena ukuran corpus uteri lebih besar dari cornua uteri dengan perbandingan 60 : 40 (Morel, 2002 dalam Jamalia, 2006).

Cervix terletak di belakang corpus uteri, berupa dinding yang tebal, dan kuat. Cervix berfungsi mengisolasi uterus dari lingkungan luar selama kebuntingan dengan membentuk barrier berupa mucus yang sangat kental. Pada stadium diestrus kuda dewasa yang tidak aktif, cervix berkontraksi sangat kuat, berwarna putih dengan panjang 6-8 $\mathrm{cm}$ dan diameter 4-5 $\mathrm{cm}$, sekresi cervix sedikit dengan konsistensi kental. kondisi otot dan ukuran cervix sangat dipengaruhi oleh perubahan homonal (Morel, 2002 dalam Jamalia, 2006).
Vagina kuda mempunyai panjang 18-23 $\mathrm{cm}$ dan diameter 10-15 $\mathrm{cm}$. Pada bagian dalam tubuh vagina diselimuti oleh peritoneum dan dikelilingi jaringan ikat longgar, lemak dan buluh darah. Vulva merupakan organ paling luar dalam saluran reproduksi. Bagian dalam dilapisi membran mukous dan berhubungan dengan vagina. Bagian atas vulva (dorsal comissure) berjarak $7 \mathrm{~cm}$ dari anus, sedangkan bagian bawah (ventral comissure) terdapat clitoris (Morel, 2002 dalam Jamalia, 2006).

Gigi kuda dapat digunakan untuk menerka umurnya secara cermat, sehingga para pengusaha pacuan mempunyai ahli atau spesialis untuk penentuan umur kuda. Seekor kuda mempunyai gigi susu yang kemudian akan berganti dengan gigi tetap. Gigi tetap mulai muncul pada umur 2,5 tahun. (Blakely and Bade, 1998). Jacoeb (1994) menambahkan kuda mempunyai enam gigi depan atas dan enam gigi depan bawah, gigi seri setelah pada umur tiga tahun telah lengkap. Pada umur empat tahun tinggal satu pasang gigi seri dan menjadi lengkap pada umur lima tahun. Setelah umur lima tahun pengamatan yang rinci yaitu dengan melihat keausan ujung serta sudut seri. Evans et al. (1977) menyatakan rumus gigi dari seekor kuda dewasa adalah :

Jantan : $2\left\{1 \frac{3}{3} C \frac{1}{1} P \frac{3 \text { atau } 4}{3} M \frac{3}{3}\right\}=40$ atau 42

Betina : $2\left\{1 \frac{3}{3} C \frac{0}{0} P \frac{3 \text { atau } 4}{3} M \frac{3}{3}\right\}=38$ atau 40

Menurut Bradley (1981) idealnya kuda dikembangbiakkan mulai umur tiga tahun. Ditambahkan oleh Toelihere (1985) kuda betina sebaiknya tidak boleh dikawinkan sebelum berumur dua tahun atau tiga tahun. Menurut Bradley (1981) idealnya kuda dikembangbiakkan mulai umur tiga tahun, pada saat kondisinya dalam keadaan bagus. Jika memelihara Brood Mares (anak-anak kuda betina) tidak dikembangbiakkan sampai berumur tiga tahun. Pendapat Frandson (1992) kuda dara sebaiknya dikawinkan untuk pertama kali pada umur 2-3 tahun.

Allen dan Antezak (2000) mengemukakan bahwa pengetahuan tentang lama periode bunting pada ternak kuda dan kemampuan 
untuk memprediksi waktu kelahiran anak kuda merupakan hal yang penting bagi keberhasilan beternak kuda, waktu bunting biasanya \pm 11 bulan. Sebelumnya dilaporkan Evans (1977), Harper (1999) bahwa rata-rata periode kebuntingan ternak kuda adalah berkisar dari 335 340 hari, ditambah lagi bahwa pengamatan terhadap kuda Morgan bahwa rata-rata lama bunting adalah 300-385 hari dengan rata-rata 339,6 hari.

Menurut Adrianis (2003) bahwa kuda betina yang dikawinkan dengan pejantan Thoroughbred di Sumbar menunjukan lama bunting rata-rata $329,27 \pm 9,71$ hari yang terdiri dari 325,55 $\pm 8,25$ hari untuk kandungan anak betina dan $355,65 \pm 10,65$ hari pada kandungan anak jantan. Ditambahkan Hunter (1995) bahwa lama bunting pada kuda adalah 335 hari dengan kisaran antara 320-341 hari, dimana musim mempengaruhi lama kebuntingan pada kuda. Harper (2000) mengemukakan pentingnya peraturan terhadap induk kuda yang kondisinya kurang baik untuk mendapatkan turunan yang diinginkan.

Berahi pasca beranak pada kebanyakan hewan terjadi pada waktu sekitar 2 minggu setelah melahirkan, meskipun anaknya masih aktif menyusui. Kuda biasanya datang estrus 5-10 hari setelah beranak. Sama dengan pendapat Jacoeb (1994) berahi pertama biasanya akan terjadi 5-10 hari setelah melahirkan dan terkadang biasa lebih lama dari keadaan yang normal. Rata-rata muncul berahi pertama setelah melahirkan adalah 9 hari.

Menurut Toelihere (1985) pada kuda inolusi uteri terjadi pada 20-40 hari sesudah partus, karena estrus pertama sesudah partus terjadi pada waktu 6-13 hari, maka uterus belum cukup berinvolusi sehingga angka konsepsi akan rendah bila dikawinkan pada saat tersebut. Tidak berbeda dengan pendapat Ensminger (1969) pada kuda setelah selesai melahirkan anak, akan kembali berahi dalam waktu 7-11 hari.

\section{METODE}

Materi yang digunakan dalam penelitian ini adalah ternak kuda betina lokal dengan turunan Thoroughbred yang ada di Kota
Payakumbuh khususnya Kecamatan Payakumbuh Utara dan Payakumbuh Timur. Jumlah sampel yang digunakan adalah 60 ekor dari populasi yang ada dan ternak kuda betina yang masih produktif yang terdiri dari 30 ekor kuda Lokal dan 30 ekor kuda turunan Thoroughbred. Ternak ini dikawinkan pada umur 3 tahun dan mempunyai catatan yang lengkap. Jumlah populasi ternak yang ada di Kecamatan Payakumbuh Utara dan Payakumbuh Timur dapat dilihat pada Tabel 1.

\section{Variabel Yang Diamati}

a. Umur kawin pertama dihitung saat hewan pertama kali dikawinkan yang dinyatakan dalam hari.

b. Lama bunting diukur sejak terakhir kali dikawinkan sampai terjadi kelahiran secara normal yang dinyatakan dalam hari.

c. Birahi kembali setelah beranak dihitung mulai dari hari selesai melahirkan sampai memperlihatkan gejala berahi kembali setelah melahirkan yang dinyatakan dalam hari.

Untuk menguji perbandingan performans reproduksi (umur kawin pertama, lama bunting dan birahi kembali setelah beranak) dilakukan dengan uji Z.

$$
z=\frac{\overline{X_{1}}-\overline{X_{2}}}{\sqrt{\frac{s_{1}^{2}}{n_{1}}+\frac{s_{2}^{2}}{n_{2}}}}
$$

$\overline{\mathrm{X}_{1}}=$ Rata - rata sampel populasi I

$\frac{\mathrm{X}_{2}}{S_{1}}=$ Rata - rata sampel populasi II

$\frac{S_{1}{ }^{2}}{S_{2}}=$ Standar deviasi sampel populasi I

$\overline{S_{2}{ }^{2}}=$ Standar deviasi sampel populasi II

$\overline{\mathrm{n}_{1}}=$ Jumlah sampel populasi I

$\overline{\mathrm{n}_{2}}=$ Jumlah sampel populasi I

Tabel 1. Jumlah Populasi Kuda Jantan dan Kuda Betina di Kota Payakumbuh

\begin{tabular}{lccc}
\hline Kecamatan & Jantan & Betina & Jumlah \\
\hline $\begin{array}{l}\text { Payakumbuh } \\
\begin{array}{l}\text { Utara } \\
\text { Payakumbuh } \\
\text { Timur }\end{array}\end{array}$ & 23 & 157 & 180 \\
\hline Jumlah & 68 & 140 & 185 \\
\hline $\begin{array}{l}\text { Sumber: Dinas Peternakan Kota } \\
\text { Payakumbuh }\end{array}$ &
\end{tabular}




\section{HASIL DAN PEMBAHASAN}

\section{Identitas Peternak Kuda di Kota Payakumbuh Aspek Teknis di Lapangan}

\section{Tata laksana pemeliharaan}

a).Membersihkan Kandang

Peternak kuda pacu selalu membersihkan kandang dua kali sehari yaitu pagi hari pada jam 08.00 - 09.30 dan sore hari pada jam 16.00 - 17.30. Berlainan dengan peternak kuda bendi yang hanya membersihkan kandang satu kali sehari yaitu di pagi hari saat kuda bendi tersebut dibawa untuk menambang.

b). Memandikan Kuda

Kuda yang tidak dipekerjakan biasanya dimandikan satu kali 15 hari atau satu kali 30 hari. Pada kuda yang masih dibawa berpacu biasanya dimandikan dua kali seminggu. Sedangkan pada kuda yang dibawa untuk bendi biasanya dimandikan satu kali seminggu sebab kulit kuda tersebut mengeluarkan keringat.

\section{Makanan dan minuman}

\section{a). Memberi Makan}

Semua peternak kuda yang ada di kota Payakumbuh memberi makan dua kali sehari yaitu pagi jam 08.30 - 09.30 disaat induk kuda tersebut dikeluarkan dari kandang, sore hari jam $16.00-17.30$.

b). Sumber Air

Air minum yang diberikan pada ternak kuda berasal dari ledeng (air PAM), air sumur bor, air tabek, air lubuk dan air hujan. Air minum diberikan secara ad libitum dengan menggunakan ember.

\section{c). Bahan Makanan Yang Diberikan}

Biasanya para peternak kuda bendi memberikan bahan makanan pokok bagi kudanya adalah : rumput, sagu, dedak dan tambahan sekali-kali jagung dan padi. Bahan makanan bagi kuda pacu biasanya banyak dan ini tergantung kepada peternak masing-masing yang menginginkan komposisi yang pas bagi ternaknya. Bahan makanan diberikan antara lain : Rumput, dedak, brand, jagung, suskaina, pelet royal horse, oats dan kacang hijau.

\section{Perkandangan}

Semua kandang kuda dewasa yang ada di kota Payakumbuh, satu kandang ditempati oleh satu ekor kuda. Semua kandang pada kuda penelitian atap terbuat dari seng dan alas kandang dari sebuk gergaji. Dinding kandang kuda pacu memiliki dinding yang terbuat dari beton, sedangkan dinding kandang kuda bendi ada yang terbuat dari beton, kayu dan bambu.

\section{Sifat Reproduksi}

Dari Tabel 2 terlihat bahwa rata-rata umur kawin pertama pada ternak kuda Lokal lebih singkat dibandingkan dengan ternak kuda Thorougbred yaitu 26,2 dan 51,8 bulan. Hal tersebut sesuai dengan pendapat Blakely dan Bade (1991), yang menyatakan bahwa kuda betina akan mencapai pubertas atau dewasa kelamin pada umur 12 sampai dengan 15 bulan, akan tetapi sebaiknya kuda betina tidak dikawinkan sebelum mencapai umur dua tahun atau bahkan akan lebih baik setelah mencapai umur tiga tahun.

Tabel 2. Umur Kawin Pertama Kuda Penelitian di kota Payakumbuh

\begin{tabular}{cccc}
\hline \multirow{2}{*}{ Keterangan } & \multirow{2}{*}{ Simbol } & \multicolumn{2}{c}{ Ternak Kuda } \\
\cline { 3 - 4 } & & lokal & Thorougbred \\
\hline Jumlah & $(n)$ & 30 & 30 \\
$\begin{array}{c}\text { Sampel } \\
\text { Rata- rata } \\
\text { (bulan) }\end{array}$ & $(\bar{X})$ & 26,2 & 51,8 \\
$\begin{array}{c}\text { Standar } \\
\text { Deviasi }\end{array}$ & $(S d)$ & 8,53 & 14.5 \\
\hline
\end{tabular}

Tingginya angka rata-rata umur kawin pertama ternak kuda pada penelitian ini mungkin disebabkan oleh beberapa faktor, yaitu faktor manajemen pemeliharaa, pemberian pakan dan faktor genetik ternak kuda. Munculnya pubertas pada ternak juga dapat dipengaruhi oleh bangsa, umur dan ukuran tubuh ternak. Pada penelitian ini lama umur kawin pertama pada ternak kuda juga dapat dipengaruhi oleh pola pikir peternak dengan memelihara ternak kuda secara intensif sehingga kebiasaan peternak untuk menunda 
mengawinkan kudanya dengan alasan bahwa kuda akan diajak latihan berpacu dan belum untuk dikembangbiakan. Rata-rata peternak tidak mau mengawinkan kudanya pada umur muda walaupun pubertas telah tercapai. Sedangkan bagi pemilik kuda bendi, keterlambatan perkawinan ini disebabkan sangat banyaknya uang yang harus dikeluarkan untuk mengawinkan kudanya.

Nilai Z hitung pada umur kawin pertama adalah sebesar $-8,33$, nilai ini lebih kecil dari 1,96 sehingga dapat disimpulkan bahwa $\mathrm{H}_{1}$ diterima. Hal ini menunjukan bahwa rata-rata umur kawin pertama pada kuda Lokal lebih singkat dibandingkan dengan kuda Thoroughbred.

Tabel 3. Lama Bunting Kuda Penelitian di kota Payakumbuh

\begin{tabular}{cccc}
\hline \multirow{2}{*}{ Keterangan } & Simbo & \multicolumn{2}{c}{ Ternak Kuda } \\
\cline { 3 - 4 } & 1 & Lokal & Thorougbred \\
\hline Jumlah & $(n)$ & 30 & 30 \\
$\begin{array}{c}\text { Sample } \\
\text { Rata- rata } \\
\text { (hari) }\end{array}$ & $(\bar{X})$ & 323,17 & 324,37 \\
$\begin{array}{c}\text { Standar } \\
\text { Deviasi }\end{array}$ & $(S d)$ & 8,55 & 14,185 \\
\hline
\end{tabular}

Pada Tabel 3 terlihat bahwa rata-rata lama bunting antara kuda Lokal dan kuda Thoroughbred tidak jauh berbeda yaitu 323,17 hari dan 324,37 hari. Menurut Blakely dan David (1991) rata-rata lama bunting seekor kuda betina adalah 335 hari dengan kisaran 315 sampai 350 hari.

Nilai $\mathrm{Z}$ hitung pada lama masa bunting adalah sebesar -0,40, nilai ini lebih besar dari 1,96 sehingga dapat disimpulkan bahwa $\mathrm{H}_{1}$ di tolak dan $\mathrm{H}_{0}$ diterima. Hal ini menunjukan bahwa rata-rata lama bunting pada kuda Lokal hampir sama dengan lama bunting kuda Thoroughbred.

Berdasarkan hasil wawancara dan pengamatan lansung di lapangan terhadap berahi kembali setelah beranak pada kuda Lokal dan kuda Thoroughbred masing masing adalah 16,37 dan 10,9 hari. Nilai $Z$ hitung pada lama berahi kembali setelah beranak adalah sebesar 2,609 , nilai ini lebih besar dari $-1,96$ sehingga dapat disimpulkan bahwa $\mathrm{H}_{1}$ di tolak dan $\mathrm{H}_{0}$ diterima. Hal ini menunjukan bahwa rata-rata berahi kembali setelah beranak pada kuda Lokal lebih lama dibandingkan dengan berahi kembali setelah beranak pada kuda Thoroughbred.

Tabel 4. Berahi kembali setelah beranak Kuda Penelitian di kota Payakumbuh

\begin{tabular}{cccc}
\hline \multirow{2}{*}{ Keterangan } & \multirow{2}{*}{ Simbol } & \multicolumn{2}{c}{ Ternak Kuda } \\
\cline { 3 - 4 } & & Lokal & Thorougbred \\
\hline Jumlah & $(n)$ & 30 & 30 \\
$\begin{array}{c}\text { Sample } \\
\text { Rata- rata } \\
\quad \text { hari) }\end{array}$ & $(\bar{X})$ & 16,37 & 10,9 \\
$\begin{array}{c}\text { Standar } \\
\text { Deviasi }\end{array}$ & $(S d)$ & 9,37 & 6,64 \\
\hline
\end{tabular}

\section{KESIMPULAN}

1. Umur kawin pertama pada kuda Lokal penelitian rata-rata $26,2 \pm 8,53$ bulan sedangkan pada kuda turunan Throughbred didapat rata-rata $51,8 \pm 14,5$ bulan.

2. Lama bunting kuda Lokal penelitian pada rata-rata $323,17 \pm 8,55$ hari sedangkan pada kuda turunan Throughbred didapat rata-rata 324,37 $\pm 14,185$ hari.

3. Birahi kembali setelah beranak pada kuda Lokal penelitian rata-rata $16,37 \pm 9,37$ hari sedangkan pada kuda turunan Throughbred didapat rata-rata $10,9 \pm 6,64$ hari.

\section{DAFTAR PUSTAKA}

Adrianis, T. 2002. Perbandingan Penampilan Reproduksi Kuda Betina Hasil Grading Up G1, G2 Thoroughbred dan Kuda Lokal di Bukittinggi dan Sekitarnya. Thesis. Pascasarjana Universitas Andalas. Padang.

Allen, W.R and D.F. Antezak. 2000. Reproduction and Modern Breeding Technologi in the mare. In The Genetics Of The Horse. CABI Publishing. New York. USA. P 307- 342. 
Blakely, J and H.B. David. 1991. Ilmu Peternakan. Edisi Keempat. Gadjah Mada University Press, Yogyakarta.

Blakely, J and D.H. Bade. 1998. Ilmu Peternakan. Edisi Keempat. Gadjah Mada University Press, Yogyakarta.

Bradley, M. 1981. Horse A Practical and Scientific Approach University of Missouri. Columbia. McGraw-Hill Book Company.

Dinas Peternakan. Propinsi Sumbar. 1989. Laporan Penerimaan dan Pendistribusian Kuda Jantan Bantuan Presiden RI. Laporan. Padang.

Ensminger, M.E. 1969. Animal Science, Animal Agricultural Series. 6 th. Ed. The Interstate Printers \& Publisher, Inc, Danville Illions.

Evans, J.W. 1977. Anatomy and Physiology of Reproduction in The Mare. In The Horse. W. H. Freeman and Company. USA.P. 351-378.

Evans, J.W. 1977 Anthony, Harold F. Hintz and L. Dale Van Vleck. 1997. The Horse. W.H. Freeman and Co., San Francisco.

Frandson, R. D. 1992 Anatomi dan Fisiologi Ternak. Edisi ke Empat. Fakultas Peternakan Dipenogoro. Gajah Mada University Press. Yogyakarta.

Harper, F. 1999. Let's not Overproduce Horses. Horse Information Series. Horse http://animalscience.ag.utk.edu/horse/re pro. Htm. 8/82004.
Harper, F. 2000. Dry Wheather Management Of Horse On Pasture. Horse Information series. http:// animalsciense.ag.utk.edu /horse/repro. Htm 8 /8/2004.

Hunter, R.H.F. 1995. Fisiologi dan Teknologi Reproduksi Hewan Betina Domestik (Terjemahan oleh DK Harya Putra) Penerbit ITB Bandang dan Universitas Udayana.

Jacoeb, T. N. 1994. Budidaya Ternak Kuda. Kanisius. Yogyakarta.

Jamalia. R. 2006. Kajian Karakteristik Anatomi dan Morfometri Organ Reproduksi Betina Kuda Lokal Indonesia. Fakultas Kedokteran Hewan. Institut Pertanian Bogor. Bogor.

Manan, D. 2002. Ilmu Kebidanan Pada Ternak. Proyek Peningkatan Penelitian Pendidikan Tinggi. Director Jenderal Pendidikan Tinggi Departemen Pendidikan Tinggi Nasional.

Pordasi. 1990. Identifikasi Penanganan Reproduksi Untuk Mencegah Kerugian Pada Tahap Perkawinan Kuda Pacu. Seminar Sehari Masalah dan prospek Pengembangan Ternak Kuda. Fakultas Peternakan Universitas Andalas dan Provinsi Sumbar.

Silver, C. 1976. Guide to The World. Exeter Book. New York.

Toelihere, M.R. 1985. Fisiologi Reproduksi Pada Ternak. Penerbit Angkasa Bandung. 